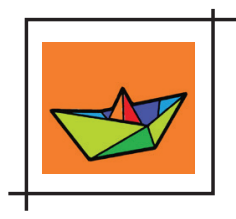

\title{
SOBRE ARTESÃOS E OFICINAS: PEDAGOGO SOCIAL, UM ARTÍFICE DA EDUCAÇÃO
}

\author{
Margareth Martins de Araújo*
}

Resumo: 0 presente artigo é fruto de reflexões acumuladas ao longo das últimas décadas de pesquisa na área de Pedagogia Social. Apresenta uma discussão sobre atividades de oficinas e ampliação do seu conceito para metodologia teórico-prática, sendo um instrumental importante à formação do educador social. Inspirado na lógica da inclusão, contém reflexões oriundas de práticas voltadas à emancipação humana, pautadas na educação como direito, na justiça restaurativa, na pedagogia da convivência e na cultura da paz, além de examinar a assertiva de não haver trabalho manual que prescinda de trabalho intelectual, apontando ser o pedagogo social, antes de tudo, um teórico-prático.

Palavras-chave: Pedagogia Social. Formação de educadores reflexivos. Justiça restaurativa. Educação. Inclusão.

\section{ARTÍFICES: MATÉRIA-PRIMA DA ARTE DO SABER-FAZER}

Procuro ser um artesão das palavras. Escrevo e reescrevo continuamente cada parágrafo, dia e noite, como fosse um escultor compulsivo. Augusto Cury

Somos integrantes do Grupo de Ensino, Pesquisa e Extensão em Formação Inicial e Permanente de Educadores de Jovens e Crianças em Situação de Vulnerabilidade Social da Universidade Federal Fluminense (Pipas-UFF). Formamos educadores sociais da Faculdade de Educação da UFF (Feuff) há 18 anos. Para tanto, buscamos compreender o motivo pelo qual, em nossa sociedade, a violação dos direitos humanos ocorre muito antes da entrada das crianças na escola e perdura por toda a vida. Com base nesse viés reflexivo, trabalhamos para construir uma formação que considere a exclusão desses indivíduos e auxilie no processo de superação das condições de indigência em que se encontram.

\footnotetext{
* Doutora em Educação pela Universidade Federal Fluminense (UFF). Professora no departamento Sociedade, Educação e Conhecimento (SSE) da Universidade Federal Fluminense (UFF).
} 
Trata-se de uma tarefa desafiadora que nos instiga constantemente a buscar na realidade de crianças e jovens que estão em situação de vulnerabilidade, camada da população-alvo das mazelas sociais, pistas para nos auxiliar a compreender a realidade na qual estão imersos, a fim de melhor formar seus educadores. Desse modo, coloca-se em diálogo a realidade encontrada com a teoria estudada, fazendo do educador social um teórico-prático, comprometido em contribuir para a realização de um processo educativo que, seja dentro ou fora da escola, se preocupa com a emancipação desses seres humanos.

Ao adotarmos a Pedagogia Social como tema de trabalho, foco do nosso interesse e questão reflexiva, percebemos quanto precisamos aprender com os sujeitos do flagelo social brasileiro para com eles trabalhar. Trata-se de milhões de crianças e jovens alijados de um processo do qual, talvez, seus próprios pais e avós também tenham sido. Embora possa parecer uma "questão hereditária", trata-se de um processo histórico de exclusão, que, ao longo dos anos, transforma em marginais seres humanos capazes, competentes e brilhantes.

"Pedagogia Social na Veia: uma pedagogia necessária" é um trabalho que tem circulado pelo Brasil com o objetivo de divulgar a importância da Pedagogia Social, em espaços formais e não formais, como uma pedagogia sensivel, humanizada, dialógica, política, teórico-prática e necessária para crianças, jovens, adultos, idosos, familiares e educadores.

Trabalhar com oficina em encontros, aulas, seminários e congressos é altamente pedagógico; isso nos leva à superação, ao novo e à produção científica. Longe de ser uma "atividade menor", como alguns consideram, ela nos desafia ao diálogo entre o pensar e o fazer, o ser e o estar, a teoria e a prática. Ao nos colocar em contato direto com os educadores sociais, com os quais trabalhamos, chama-nos para a roda e convoca-nos ao diálogo. 0 monólogo não tem espaço nas oficinas e ouvir o outro e considerar o dito se impõem.

Cabe então perguntar: qual seria a diferença entre coordenar uma oficina e realizar uma palestra, por exemplo? Seria uma atividade mais importante do que a outra, ou será mero equívoco das nossas mentes cartesianas a pregar-nos uma peça? Existe de fato uma hierarquia na produção da ciência ou trata-se de um engodo a envaidecer-nos? 0 que de fato ocorre entre uma e outra? Exigem níveis de preparação diferenciados entre ambas? Há níveis distintos entre o monólogo e o diálogo, ou estamos falando de status acadêmico? 0 que de fato está em jogo entre uma e outra? Será que é a antiga e equivocada distinção entre trabalho manual e intelectual? Ainda há muito que se examinar sobre essa questão, mas a Pedagogia Social nos informa não ser de bom alvitre polarizar, mas, sim, detectar quanto uma e outra podem dialogar e guardam mais semelhanças do que dissemelhanças.

Nessa arena de embates, as ideias, como em um caleidoscópio, constroem múltiplas e complexas configurações à medida que os educadores sociais dialogam, ampliam o campo de visão, examinam o conhecimento prático e produzem teoria. As oficinas, para nós, educadores sociais, são atividades que traduzem um permanente diálogo teórico-prático e uma 
forma inovadora de produzir ciência. Cuida-se de um momento altamente desafiador para quem coordena e para os demais integrantes da oficina, conforme dito por Freire (1987, p. 68): "Não há saber mais ou saber menos: há saberes diferentes. Aqui todos portam conhecimento a ser compartilhado. Todos são capazes. Todos podem!".

Por ser altamente desafiadora, a oficina exige de quem coordena uma postura de humildade perante o seu próprio conhecimento, e exige que ele/ela se abra às novas formas de produzir conhecimento. Exige celeridade e expertise por parte de todos. Agrega talentos e possibilidades. Envolve competências múltiplas e perspectiva de futuro. 0 correr riscos se faz presente a todo o momento. Lidar com o devir se faz necessário durante todo o processo. Exige planejamento, e não engessamento.

A oficina assume um caráter social e pedagógico ao socializar o conhecimento in natura, de forma coletiva, e em seu nascedouro. Ao transbordar conhecimento e reverter-se em perspectiva de futuro, realizam-se reflexões teórico-práticas, emanadas dos artesãos que nela trabalham, com afinco, para o sucesso de educadores e educandos. Ela é fonte de criação, inovação e superação ao nos exortar a saber mais e desafiar-nos ao infinito.

É uma atividade que não pode ser apenas planejada. Incansavelmente, exorta-nos a sair da perspectiva cartesiana da nossa formação e ousar a ampliar nossas próprias habilidades. É nessa hora que o pesquisador pedagogo social se pergunta: por que não? Assim, abrimos um leque de novas possibilidades de interligar o mundo, dialogando com ele. É de peito aberto, cônscios das possibilidades e impossibilidades, com as quais nos deparamos nessa metodologia de produção de conhecimento. É de forma humilde e sabedores de que o sabido é infinitamente menor do que os não sabidos.

Nós, da Pedagogia Social, assumimos a oficina como metodologia de estudo, pesquisa, trabalho e produção de conhecimento, por compreender tratar-se de uma atividade que está no mundo e com ele interage de forma a extrair aprendizados. Aprender com o seu movimento, com a sua pedagogia e, em especial, com a sua forma de nos ensinar. 0 mundo, como um livro aberto, traz a vida como mestra e a oficina, como metodologia epistêmica.

É uma honra para nós, da Pedagogia Social, poder contar com uma metodologia de trabaIho ousada, integradora e capaz de levar-nos ao não conhecido, ao não visto, ao impensado. Dessa forma, chegamos a ver o ainda não visto, e trabalhar nessa direção se torna um ato de ousadia. Assim, nós, educadores sociais, "lançamos nossa rede em águas mais profundas", em busca do conhecimento profundo. Concebemos conhecimento profundo como um conhecimento não aparente, não superficial e de difícil percepção. 


\section{OBRA DE ARTESÃO}

A mente que se abre para uma nova ideia jamais voltará ao seu tamanho original. Albert Einstein

0 conceito de vulnerabilidade com o qual trabalhamos aponta para pessoas ou famílias que estão em processo de exclusão social, principalmente por fatores socioeconômicos. 0 estado de vulnerabilidade social é marcado por condições precárias de moradia e saneamento, os meios de subsistência inexistentes e a ausência de um ambiente familiar, por exemplo. Compreendemos risco social como o período da vida do ser humano em que há desequilibrio socioeconômico.

A pedagogia social com a qual trabalhamos aponta para a necessidade imperativa de 0 educador se interessar pela biografia do educando, buscando compreendê-la e, ao fazer isso, responsabilizar-se por contribuir positivamente com o futuro dele. É mais do que transmitir conhecimentos. 0 que se pretende é, ao transmitir conhecimentos, disseminar valores e educar por meio do exemplo. É uma pedagogia que exige convivência e diálogo, acarretando experiência.

O ser humano, independentemente da classe social, ao longo da sua existência, sempre está exposto a alguma espécie de vulnerabilidade. Nunca há segurança total, certeza total, capacidade total. Há sempre o devir a nos espreitar, a lembrar-nos do inacabamento e da probabilidade da vida. A pedagogia social trabalha exatamente com esse espaço-tempo, fazendo-se presente de forma preventiva, processual e curativa quando necessário. Somos, enquanto educadores sociais, artífices do tempo quântico, no qual passado, presente e futuro coexistem. Por esse motivo, ouvir as pessoas e apostar em suas histórias de vida sempre nos importa.

Fiori (2011, p. 45) ajuda-nos a pensar na história de vida das pessoas como um "processo em que a vida como biologia passa a ser vida como biografia". Compreender vida como biografia auxilia o educador social a construir proposições de atividades que incorporem esse conceito como metodologia de trabalho, ampliando a possibilidade de comunicação, locução e interlocução na interação entre os sujeitos da educação.

Essa concepção de educação aponta para o compartilhamento de ideias. É um processo por meio do qual todos têm direito à voz, e a fala funciona como um pleno exercício de poder ser, poder ter, poder existir. Falamos sobre uma trilogia que compõe uma atividade pedagógica capaz de pressupor a identidade do ser como fundamento epistêmico e social.

Nesse processo pedagógico, as histórias de vida são valoradas e o aprender a falar é tão importante quanto o aprender a ouvir. A partir desse ponto de vista, o respeito pelas histórias e memórias das vidas que se tecem paulatinamente passa a ser uma importante categoria de trabalho. Saber falar e ouvir nos remete à conversa, ao encontro e ao diálogo. 
Para Paulo Freire (1987), ao pôr o diálogo em prática, o educador não pode se colocar na posição ingênua de quem se pretende detentor de todo o saber. Deve, antes, colocar-se na posição humilde de quem tem consciência de que não sabe tudo e reconhece que o analfabeto não é um homem perdido, fora da realidade, mas alguém quem tem experiência de vida e, portanto, é um ser.

\title{
NARRATIVAS DE ARTESÃOS
}

\author{
Uma vivência, algo pelo qual simplesmente eu passei, eu \\ atravessei, algo que me aconteceu, ela não é nada se ela \\ não puder ser transformada em alguma narrativa \\ compartilhável e transmissivel ao grupo ao qual eu \\ pertenço. Éa transmissão, é o compartilhar, que \\ transforma a vivência em experiência. \\ Walter Benjamin
}

Até agora tratamos do encontro do artífice com sua obra, encontros marcados por possibilidades e impossibilidades, por planejamento e metodologias que expressem cada vez mais o sentido/vivido. Falamos da obra do artesão. Toda obra nos leva a algum lugar e, longe de ser o fim, marca um recomeço, uma inspiração para novas obras das quais passaremos a tratar.

Toda atividade de oficina, como toda atividade acadêmica, visa à produção textual. Assim, procuramos abrir os guardados da pesquisa elaborados em oficinas ao longo de algumas décadas em diálogo com as oficinas realizadas pelo grupo Pipas-UFF. Não obstante, é possível revelar o potencial intelectual de uma metodologia de pesquisa como essa, capaz de ampliar os horizontes formadores em níveis diferenciados de coleta de dados e de reflexão sobre esses. A pesquisa-ação se faz presente nesse e em outros inúmeros processos que envolvem a Pedagogia Social.

Coordenar uma oficina, independentemente do tema e do evento no qual esteja inserida, demanda cautela, determinação e flexibilidade em consonância com o movimento intelectual advindo da realização dela. A tarefa é complexa e envolve diálogo permanente, exposição pessoal e intelectual e traz como seu maior desafio a articulação teórico-prática dos temas emergentes. A pessoa que a coordena é retirada da sua "zona de conforto" e vê-se obrigada a trabalhar com o inesperado, o não planejado, o aleatório, em dinâmicas constantes de produção diferenciadas de conhecimento. Há de se construir habilidades de trabalho em grupo e coletivo, nas quais as múltiplas, variadas e complexas lógicas se fazem presentes. Essa tarefa exige a capacidade de trabalhar com a diferença e a inclusão, sob a perspectiva de não ser a nossa a única lógica existente. 
Como o mote da oficina é teórico-prático, a produção textual faz-se presente como necessidade imperiosa desse saber fazer. É exatamente nesse ponto que o coordenador, na posse de suas atribuições, solicita o registro do vivido/compreendido, em forma de apontamentos mais apropriados para cada participante. Nosso compromisso é a produção escrita individual em articulação com a produção escrita coletiva, movimento que exige a percepção de que o todo é muito mais do que a soma das partes. Torna-se o momento de detectar os múltiplos talentos existentes, para que por meio da expertise de cada componente da oficina cheguemos a um todo organizado. Isso exige maestria por parte do coordenador e o exercício de múltiplas habilidades adquiridas no decorrer de muitos anos de realização de oficinas. Cada oficina é única, porém é preciso buscar o generalizável.

É possivel detectar nas oficinas um forte componente de potencialização dos seus integrantes, uma vez em que há, nessa atividade, o fortalecimento de todos os envolvidos. Todos se percebem capazes de contribuir, cada um do seu jeito, cada um de uma forma, mas todos podem deixar sua marca pessoal em todas as fases do processo de uma oficina. Trata-se, portanto, de uma atividade de inclusão, na qual talentos são descobertos e potencialidades são expostas. Ninguém deve ficar sem contribuir para o coletivo e faz-se necessária uma concepção de convívio humano na qual múltiplos saberes dialoguem, sem competição.

Vivenciamos em oficinas a revelação de um saber poder, muitas vezes calado e desqualificado por certos modelos de ciência e de escola. Nessa perspectiva, na qual todos podem, desde que queiram, há um aspecto promotor de liberdade de expressão e autonomia por meio do qual cada um se descobre a partir do não sabido e do intuído. As pessoas se potencializam e descobrem-se portadoras de novas possibilidades de ser e de estar no mundo. Com a metodologia de pesquisa em oficinas, é possível afirmar o direito do exercício pleno do devir humano, ultrapassando as barreiras impostas pela interdição de políticas públicas equivocadas para a formação do educador social. A oficina é, antes de tudo, um espaço-tempo de saber fazer, de saber poder e de potencializar.

A cada oficina realizada há novos achados, novas descobertas, novas desconstruções e construções. Longe de ser a panaceia da educação, a oficina é uma metodologia de trabalho altamente afinada com a concepção do pesquisador educador social, aquele profissional intelectual em processo contínuo de formação.

É um espaço-tempo de múltiplas configurações, no qual o ser está a serviço da ação humana no mundo, descomprometido com a competição, exclusão e submissão de muitos. Falamos de um pleno processo de pesquisa revelador das potencialidades do ser, associado ao vir a ser, constante em nossas vidas, não havendo espaços para competição, ranking ou pódios. Trata-se de um movimento de construção coletiva por meio do qual ampliamos nossas potencialidades em diálogo com a ampliação das possibilidades do grupo. Assim, percebemos que o avanço do todo está diretamente vinculado ao avanço do indivíduo, não havendo um sem o outro. Nesse processo, compreendemos que o ser humano faz parte de uma 
comunidade de destino, na qual todos crescem com o crescimento de um e todos decaem com a queda de um.

No ponto em que nossas reflexões agora se encontram, é possível afirmar a existência de um vislumbre de felicidade para a raça humana, pois percebemos, por meio do diálogo entre o todo e as partes, a possibilidade de o exercício de humanidade se direcionar à pesquisa e aos pesquisadores. É um privilégio perceber e atuar dessa forma. Traz sentido diferenciado à pesquisa e ao ato de pesquisar, imposto cada vez mais por práticas solidárias de superação humana. 0 pedagogo social é um artífice da educação. Falamos de outra lógica e de outra concepção de ciências, por que não?

\section{On artisans and workshops: social pedagogue, an artist of education}

Abstract: This article is the result of reflections accumulated over the last decades of research in the area of Social Pedagogy. It presentes a discussion on workshop activities and the expansion of its concept to theoretical and practical methodology, being an important tool for the formation of the social educator. Inspired by the logic of inclusion, it contains reflections from practices aimed at human emancipation, based on education as a right, restorative justice, the pedagogy of coexistence and the culture of peace, in addition to examining the assertion that there is no manual work that does not require intellectual work, indicating that the social pedagogue is, above all, a theoretical-practical.

Keywords: Social Pedagogy. Formation of reflective educators. Restorative justice. Education. Inclusion.

\section{REFERÊNCIAS}

ARAÚJ0, M. M. de. Pedagogia social: diálogos com crianças trabalhadoras. São Paulo: Expressão e Arte Editora, 2015. v. 8.

FIORI, E. M. Aprender a dizer a sua palavra. In: FREIRE, P. Pedagogia do oprimido. Rio de Janeiro: Paz \&t Terra, 2011. p. 25.

FREIRE, P. Pedagogia da autonomia. Rio de Janeiro: Paz \& Terra, 2010.

GADOTI, M. (org.) Paulo Freire: uma biobibliografia. São Paulo: Cortez: Instituto Paulo Freire, 1996.

HOWARD, G. Teoria das inteligências múltiplas. São Paulo: Companhia das Letras, 2004.

JARES, X. R. Educar para a paz em tempos dificeis. Tradução Elisabete de Moraes Santana. São Paulo: Palas Athena, 2007.

JARES, X. R. Pedagogia da convivência. Tradução Elisabete de Moraes Santana. São Paulo: Palas Athena, 2008. 
LARROSA, J. B. Tremores: escritos sobre experiência. Tradução Cristina Antunes. Belo Horizonte: Autêntica Editora, 2016.

MELO, M. de F. A. O. Algumas aprendizagens construidas durante a brincadeira de pipa: o que está em jogo. Educação em Revista, v. 26, n. 2, 2010. DOI 10.1590/S0102-46982010000200005 ROSA, G. J. Grande sertão: veredas. Rio de Janeiro: Nova Aguilar, 1994. (Série Brasileira).

SANTOS, B. de S. Um discurso sobre as ciências. São Paulo: Cortez, 2018.

SARAMAgO, J. Ensaio sobre a cegueira. São Paulo: Companhia das Letras, 1994.

SILVA, R. da; SOUZA NETO, J. C. de; MOURA, R. A. (org.). Pedagogia social. São Paulo: Expressão e Arte, 2009.

SILVA, R. da; SOUZA NETO, J. C. de; GRACIANI, M. S. S. Pedagogia social: a pesquisa em Pedagogia Social. São Paulo: Expressão e Arte, 2017. v. 10. 1 t. 